Article

\title{
A Robust and Multi-Weighted Approach to Estimating Topographically Correlated Tropospheric Delays in Radar Interferograms
}

\author{
Bangyan Zhu ${ }^{1, *}$, Jiancheng $\mathrm{Li}^{1}{ }^{1}$, Zhengwei Chu ${ }^{2}$, Wei Tang ${ }^{3}$, Bin Wang ${ }^{1}$ and Dawei Li ${ }^{1}$ \\ 1 School of Geodesy and Geomatics, Wuhan University, 129 Luoyu Road, Wuhan 430079, China; \\ jcli@sgg.whu.edu.cn (J.L.); binwangsgg@whu.edu.cn (B.W.); dwli@sgg.whu.edu.cn (D.L.) \\ 2 Nanjing Institute of Surveying, Mapping and Geotechnical Investigation, Nanjing 210019, China; \\ zby7edgar@126.com \\ 3 State Key Laboratory of Information Engineering in Surveying, Mapping and Remote Sensing, \\ Wuhan University, Wuhan 430079, China; weitang@whu.edu.cn \\ * Correspondence: byz@whu.edu.cn; Tel.: +86-158-507-33612
}

Academic Editor: Assefa M. Melesse

Received: 4 March 2016; Accepted: 8 July 2016; Published: 12 July 2016

\begin{abstract}
Spatial and temporal variations in the vertical stratification of the troposphere introduce significant propagation delays in interferometric synthetic aperture radar (InSAR) observations. Observations of small amplitude surface deformations and regional subsidence rates are plagued by tropospheric delays, and strongly correlated with topographic height variations. Phase-based tropospheric correction techniques assuming a linear relationship between interferometric phase and topography have been exploited and developed, with mixed success. Producing robust estimates of tropospheric phase delay however plays a critical role in increasing the accuracy of InSAR measurements. Meanwhile, few phase-based correction methods account for the spatially variable tropospheric delay over lager study regions. Here, we present a robust and multi-weighted approach to estimate the correlation between phase and topography that is relatively insensitive to confounding processes such as regional subsidence over larger regions as well as under varying tropospheric conditions. An expanded form of robust least squares is introduced to estimate the spatially variable correlation between phase and topography by splitting the interferograms into multiple blocks. Within each block, correlation is robustly estimated from the band-filtered phase and topography. Phase-elevation ratios are multiply- weighted and extrapolated to each persistent scatter (PS) pixel. We applied the proposed method to Envisat ASAR images over the Southern California area, USA, and found that our method mitigated the atmospheric noise better than the conventional phase-based method. The corrected ground surface deformation agreed better with those measured from GPS.
\end{abstract}

Keywords: InSAR; tropospheric delay; least squares; robust estimation; persistent scatterer interferometry

\section{Introduction}

When microwave signals such as Interferometric Synthetic Aperture Radar (InSAR) travel through the atmosphere, they are affected by spatio-temporal variations in the atmospheric refraction [1,2], which can result in a phase advance or delay. These atmospheric noises typically come from two major sources: ionospheric and tropospheric effects. Spatio-temporal variations in density of the free electrons found in the ionosphere $(\geqslant 60 \mathrm{~km})$ cause phase advances that are more significant at higher latitudes and for larger wavelength radar signals such as the L-band SAR sensor onboard the ALOS satellite [3]. Tropospheric effects are caused by spatio-temporal variations in pressure, temperature, and water vapor content in the lower part of the troposphere $(\leqslant 5 \mathrm{~km})$, which causes phase delays that can be up to a few decimeters in magnitude and often overwhelm the deformation signal of interest [4]. 
Our study only focuses on the tropospheric delay as the ionospheric effects can be neglected in the C-band SAR images that we used in our study.

A number of methods have been developed to correct the tropospheric delay in InSAR data [5-7]. These correction techniques can be classified into two groups: methods based on auxiliary data and methods based on the interferometric phase itself. The methods producing synthetic delay maps by using auxiliary data sets directly to correct the tropospheric delay in interferograms. This includes the use of GPS wet delay measurements [8-10], local meteorological data [11], multispectral remote sensing imagery [12,13], and local or global meteorological reanalysis products [14,15]. Ground-based GPS measurements are typically sparse, while multispectral remote sensing imagery such as MODIS and MERIS can only provide measurements during daytime and has a low accuracy in the presence of clouds. The local or global meteorological models have large grid spacing; and are not sufficient for simulating smaller scale tropospheric effects such as those associated with turbulent mixing [15]. In addition, the atmospheric models are not always available at the acquisition time for each SAR image.

The phase-based methods are independent of external data sets that can be used to calculate the tropospheric phase delay from the interferogram itself. Tropospheric phase delay $\Delta \varphi_{\text {trop }}$ for an individual interferogram can be computed by assuming a linear model $\left.\left(\Delta \varphi_{\text {trop }}=K h+\varphi_{c}\right)\right)$, between the elevation $h$ and interferometric phase $\Delta \phi$. Where the elevation $h$ can be derived from the SRTM $\mathrm{DEM}, K$ is the phase-elevation ratio to be estimated, and $\phi_{c}$ represents a shift applied to the whole interferogram. The linear model has been used to correct interferograms with success in small and non-deforming areas, but it is limited, as it assumes no spatial variability in the tropospheric properties of the interferogram [16-18]. The power-law model $\left(\Delta \phi_{\text {trop }}=K^{\prime}\left(h_{0}-h\right)^{\alpha}\right)$ developed by Bekaert et al. accounts for the spatially variable signal of the tropospheric phase delay [19]. The two input parameters $h_{0}$ and $\alpha$ are estimated from balloon sounding data or weather model data, which are not always available for a study area. Another way to mitigate the tropospheric delay is to apply spatio-temporal filtering in time series analysis based on the assumption that the delay is random in time. Due to seasonal changes in the atmospheric conditions, delay sometimes is significantly correlated with time; thus spatio-temporal filtering usually used for extracting and removing tropospheric delay will not work properly. In our study, we propose a method to estimate the phase-elevation ratio $K$ in the linear model by using a robust and multi-weighted approach. Our method accounts for the spatial variability of the tropospheric phase delay by decomposing the interferogram into blocks and robustly estimating the $K$ value for each block. Compared to existing methods, our approach is relatively simple and is not dependent on the availability of external data sets, and corrects the interferograms on a scene-by-scene basis.

Robust estimation has been widely used for gross error processing in least square adjustment (LS) $[20,21]$. This method is generally easier to perform and more efficient than data snooping, especially when there are a large number of observations. Thus, it is applicable to the estimation of the ratio $K$ in the phase-elevation linear model for tropospheric correction in radar interferograms. In this paper, we introduce a robust estimation algorithm to derive topographically correlated tropospheric delays and propose a new expanded form to solve the problems caused by a massive number of InSAR pixel observations (interferometric unwrapped phases). We propose a complete solution to estimate tropospheric delays that can be applied locally to account for the spatial variability found in the troposphere. We apply our Robust and Multi-Weighted (RMW) approach to correct the interferograms over Southern California for a small area containing the Pomona basin area that has suffered from rapid subsidence due to water withdrawal.

\section{InSAR Data Set and Interferometric Processing}

To investigate the correction capability of the RMW method, we generated a single master network of 19 descending Envisat ASAR images over Southern California, USA (track 170, see Figure 1), spanning the period from 23 February 2008 until 25 September 2010. The image acquired on 18 April 2009 was selected as the common master image. From the common master image and remaining 
images, 18 differential interferograms were generated. The spatio-temporal baseline parameters of these interferograms are given in Table 1.

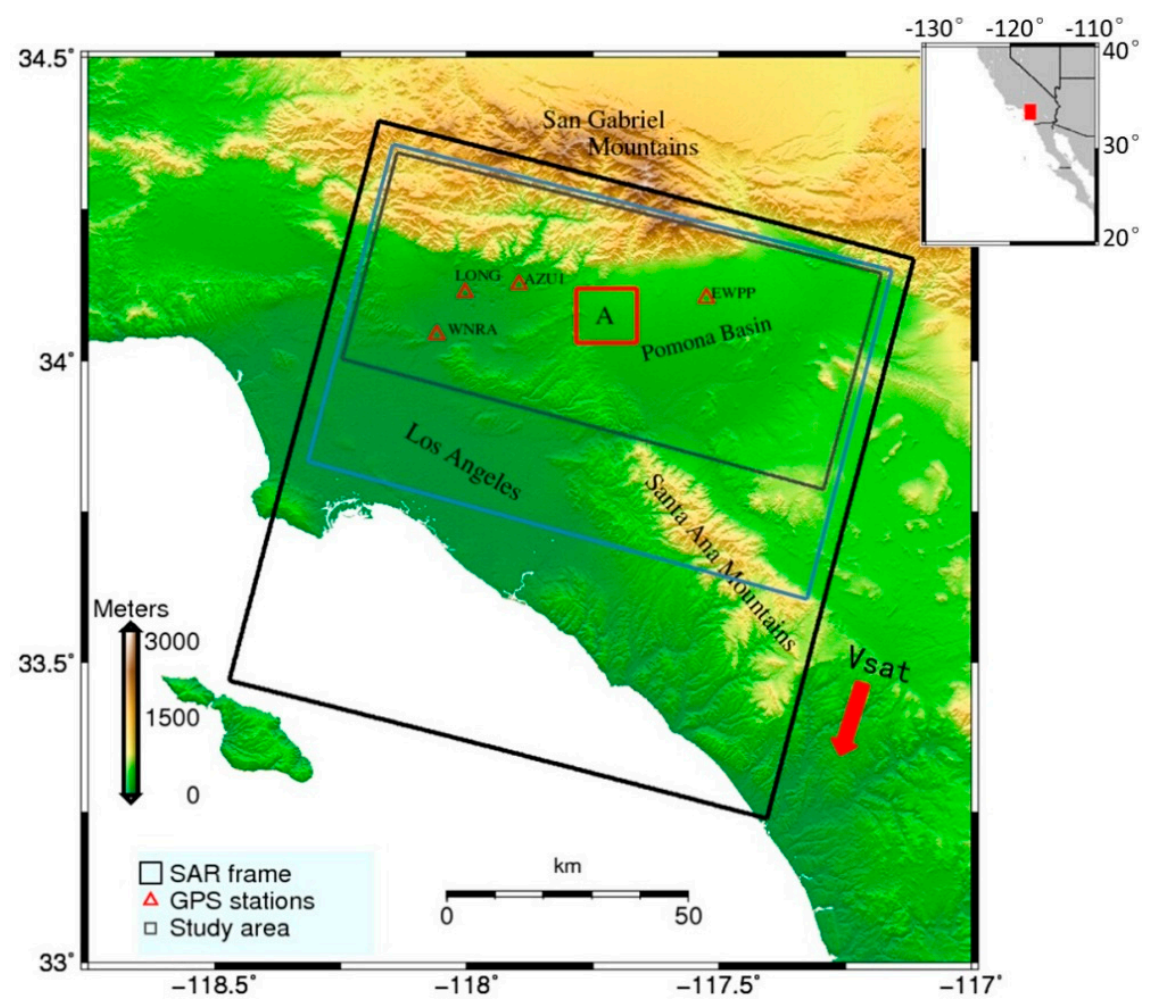

Figure 1. Data coverage for the study region. The area in black rectangle is the footprint of the whole Envisat image. The gray rectangle represents our study area and an experimental region A is denoted by red rectangle. The wider study area used to test turbulent effects is denoted by the blue rectangle. The red triangles represent the locations of GPS sites. The background is the SRTM DEM.

Table 1. Parameters of Envisat ASAR images.

\begin{tabular}{ccccc}
\hline Ifg Index & Date & $\begin{array}{c}\text { Perpendicular } \\
\text { Baseline }(\mathbf{m})\end{array}$ & $\begin{array}{c}\text { Temporal } \\
\text { Baseline (Days) }\end{array}$ & $\begin{array}{c}\text { Doppler Central } \\
\text { Baseline (Hz) }\end{array}$ \\
\hline 1 & 23 February 2008 & -95 & 420 & 9.6 \\
2 & 29 March 2008 & 439 & 385 & -1.9 \\
3 & 3 May 2008 & 91 & 350 & 7.8 \\
4 & 7 June 2008 & 308 & 315 & 0.1 \\
5 & 12 July 2008 & 364 & 280 & 0.1 \\
6 & 16 August 2008 & 284 & 245 & 4.1 \\
7 & 25 October 2008 & 272 & 175 & -3.4 \\
8 & 3 January 2009 & 288 & 105 & -0.4 \\
9 & 14 March 2009 & 692 & 35 & 1.7 \\
$\mathbf{1 0}$ & 18 April 2009 & $\mathbf{0}$ & $\mathbf{0}$ & $\mathbf{0}$ \\
11 & 23 May 2009 & 203 & -35 & -0.7 \\
12 & 27 June 2009 & 407 & -70 & 0.1 \\
13 & 1 August 2009 & 98 & -105 & -3.7 \\
14 & 5 September 2009 & 432 & -140 & -3.0 \\
15 & 14 November 2009 & 356 & -210 & -7.5 \\
16 & 3 April 2010 & 543 & -350 & 3.7 \\
17 & 8 May 2010 & 369 & -385 & -15.7 \\
18 & 12 June 2010 & 389 & -420 & -10.6 \\
19 & 25 September 2010 & 391 & -525 & \\
\hline
\end{tabular}


DORIS software was used for interferometric processing and StaMPS (Stanford Method for Persistent Scatterers) software was applied to select persistent scatterer (PS) and estimate DEM errors [22-24]. The parameters used in the StaMPS processing are listed in Table 2. We used the precise ODR orbits from Delft Institute for Earth-Oriented Space Research to minimize the orbital errors, while the Shuttle Radar Topography Mission (SRTM) digital elevation model with $90 \mathrm{~m}$ resolution was used for removing topographic phase contributions [25].

Table 2. StaMPS processing parameters.

\begin{tabular}{cccc}
\hline Parameter & Value & Parameter & Value \\
\hline DEM (SRTM) & $90 \mathrm{~m}$ & Gamma convergence & 0.005 \\
Oversample & no & Density random & 20 \\
Dispersion threshold & 0.4 & Weed STD & 1 \\
Patches number & 6 & Weed max noise & Inf \\
Max topography error & 5 & Unwrap method & '3D' \\
Select method & Density & Unwrap grid size & $200 \mathrm{~m}$ \\
\hline
\end{tabular}

\section{The RMW Tropospheric Correction Method}

\subsection{Modeling}

Tropospheric delay is related to the spatial and temporal variations in air temperature, pressure, and relative humidity in the troposphere, which can be split into hydrostatic, wet and liquid components. The wet component is the major limiting factor due to the highly unstable water vapor content in both in space and time [26,27]. Unlike the wet component, temperature and pressure are smoothly distributed in space, leading to better-resolved longer-scale wavelength hydrostatic components, which are quite stable and create about 90 percent of the total tropospheric delay. The liquid component will only become significant when the atmosphere is saturated and is expected to be quite small. This component is responsible for less than $0.1-0.4 \mathrm{~mm} / \mathrm{km}$ tropospheric delay under usual weather conditions for C-band sensors (wavelength of approximately $6 \mathrm{~cm}$ ) [28]. We focus only on combination of the hydrostatic and wet delay, neglecting the impact of the liquid water content and ionospheric electronic content (typically very small for C-band SAR data) [3]. The tropospheric phase delay $\Delta \varphi_{\text {trop }}$ for an individual interferogram can be estimated from the relationship between the interferometric phase and topography:

$$
\Delta \phi_{\text {trop }}=K h+\phi_{c}
$$

where $K$ is a constant in the phase-elevation ratio relating the interferometric tropospheric phase delay $\Delta \varphi_{\text {trop }}$ and the elevation $h$. The value $K$ is used to calculate the tropospheric signal throughout the full interferogram, and $\phi_{c}$ represents a shift applied to the whole interferogram.

However, there are two limitations in this conventional linear model (Equation (1)). First, a single relationship between phase and topography for the whole interferogram cannot account for the spatially variable tropospheric delay and second, a non-deforming region is required. In order to account for the lateral variability of the tropospheric delay, the interferograms were split into multiple blocks and the phase-elevation ratios were estimated locally for each block. The original interferometric phases are comprised of multiple signals, such as tropospheric delay, deformation, and residual orbit errors. The wavelengths of these components contain a multi-scale dependent spectrum and have different sensitivities to each other. For example, tropospheric signals contain short wavelength scale components, introduced by turbulence component in the lower part of the troposphere $(\leqslant 5 \mathrm{~km})$. The long wavelength scale components introduced by hydrostatic and wet delays are partly correlated to topography [28]. In addition, the longer wavelength scale components introduced by ground deformation such as tidal loading [29], tectonic slow slip [30], or hydrological loading [31] may be more sensitive to other different sources of confounding noises. Therefore, the selection of the band 
filter is not always trivial, as it requires empirical information about multi-scale dependent spectrums. However, we can take advantage of the fact that the tropospheric signal is present at all wavelength scales so we can estimate the phase-elevation ratio from a spatial frequency band relatively insensitive to the other signals [18]. We take consideration of the different spatial bands performance of final tropospheric results overall in our study. Based on this analysis, a $2-16 \mathrm{~km}$ spatial band was chosen over our test-region, the details are discussed in Section 4. To do this, we did not need a non-deforming region to estimate the phase-elevation ratio.

As mentioned above, we can rewrite the Equation (1):

$$
\begin{gathered}
\Delta \phi_{\text {trop, filt }}=K^{\prime} h_{\text {filt }}+\phi_{\mathrm{c}} \\
\Delta \phi_{\text {trop }}=K^{\prime} h+\phi_{c}^{\prime}
\end{gathered}
$$

where $K^{\prime}$ is a phase-elevation ratio, relating the estimated tropospheric delay based on the band-filtered phase $\Delta \varphi_{\text {trop filt }}$ and the elevation $h_{\text {filt }}$. The value $\phi_{c}$ represents a constant bias term, and $\phi_{c}^{\prime}$ represents a shift applied to the whole interferogram, estimated over multiple blocks.

To estimate the phase-elevation ratio $K^{\prime}$, we estimate this value for each block locally and then these values are multiply-weighted and extrapolated to each PS point. The local robust estimation of the phase-elevation ratio plays a critical role in increasing the accuracy of tropospheric delays. We applied an expanded form of the robust estimation method; the details of the derivational processes and our corresponding strategies for data processing are discussed in the following subsections.

\subsection{Basic Principles of the Least Squares and Robust Estimation Method}

The error equation of a linear observation model is presented as:

$$
V=A \hat{X}-L
$$

where $\boldsymbol{L}$ denotes the $m \times 1$ observation vector, $A$ represents the $m \times n$ coefficient matrix, and $\operatorname{Rank}(\mathbf{A})=n<m$. $\hat{\boldsymbol{X}}$ denotes the parameter vector to be estimated and $\boldsymbol{V}$ is the residual vector of $L$.

The adjustment principle of least squares is as below:

$$
\boldsymbol{V}^{\mathrm{T}} \boldsymbol{P} \boldsymbol{V}=\min
$$

where $\boldsymbol{P}$ denotes the weight matrix of $\boldsymbol{L}$. By solving the extreme value problem, the parameter estimator is obtained as follows:

$$
\hat{\boldsymbol{X}}=\left(\boldsymbol{A}^{\mathrm{T}} \boldsymbol{P A}\right)^{-1} \boldsymbol{A}^{\mathrm{T}} \boldsymbol{P} \boldsymbol{L}=\boldsymbol{N}^{-1} \boldsymbol{C}
$$

where $N=A^{\mathrm{T}} \boldsymbol{P} A, C=A^{\mathrm{T}} \boldsymbol{P} \boldsymbol{L}$.

When the observation vector $L$ contains gross errors, it is difficult to derive a reliable parameter solution using least squares method. Therefore, a robust estimation method based on the equivalent weight principle is introduced to solve this problem; the estimation criterion is presented as:

$$
\boldsymbol{V}^{\mathrm{T}} \overline{\boldsymbol{P}} \boldsymbol{V}=\min
$$

where $\overline{\boldsymbol{P}}$ is the equivalent weight matrix of the observation vector $\boldsymbol{L}$. The parameter estimator can be easily derived as follows:

$$
\hat{\boldsymbol{X}}=\left(\boldsymbol{A}^{\mathrm{T}} \overline{\boldsymbol{P}} \boldsymbol{A}\right)^{-1} \boldsymbol{A}^{\mathrm{T}} \overline{\boldsymbol{P}} \boldsymbol{L}
$$

We assume that observations are independent from each other, thus the $i$ th diagonal element of $\overline{\boldsymbol{P}}$ is obtained as:

$$
\bar{p}_{i}=p_{i} w_{i i}
$$

where $w_{i i}$ represents the corresponding weight factor. We use the weight factor function of IGGIII $[32,33]$ to calculate $w_{i i}$ : 


$$
w_{i i}= \begin{cases}1.0 & \left|\widetilde{v}_{i}\right| \leqslant k_{0} \\ \frac{k_{0}}{\widetilde{v}_{i} \mid}\left(\frac{k_{1}-\left|\widetilde{v}_{i}\right|}{k_{1}-k_{0}}\right)^{2} & k_{0}<\left|\widetilde{v}_{i}\right| \leqslant k_{1} \\ 0 & k_{1}<\left|\widetilde{v}_{i}\right|\end{cases}
$$

where $\widetilde{v}_{i}$ represents the $i$ th standardized residual, $k_{0}$ and $k_{1}$ are constants and can be set as $k_{0}=2.0-3.0$ and $k_{1}=4.0-8.0$, these values are set according to the specific application backgrounds. The value for $\widetilde{v}_{i}$ is calculated as:

$$
\widetilde{v}_{i}=\frac{v_{i}}{\sigma_{0} \sqrt{q v_{i}}}
$$

where $v_{i}$ denotes the $i$ th element in the residual vector $V, \sigma_{0}$ is the square root of the variance component. $q v_{i}$ indicates the $i$ th diagonal element of $Q V, Q V$ is the cofactor matrix of LS residuals, and it can be derived via cofactor propagation as below:

$$
Q \boldsymbol{V}=\boldsymbol{P}^{-1}-\boldsymbol{A}\left(\boldsymbol{A}^{\mathrm{T}} \boldsymbol{P} \boldsymbol{A}\right)^{-1} \boldsymbol{A}^{\mathrm{T}}=\boldsymbol{P}^{-1}-A \boldsymbol{N}^{-1} \boldsymbol{A}^{\mathrm{T}}
$$

The estimator of $\sigma_{0}$ obtained from the traditional formula is easily affected by gross errors; thus, the median method [34] is applied to obtain a robust estimator of $\sigma_{0}$. The formula is presented as follows:

$$
\hat{\sigma}_{0}=\underset{i=1}{m e d}\left(\left|v_{i} / \sqrt{q v_{i}}\right|\right) \cdot 1.4826
$$

The iterative procedure for robust estimation is described as below:

Step 1: Set the initial value of the equivalent weight matrix: $\overline{\boldsymbol{P}}^{(0)}=\boldsymbol{P}$.

Step 2: Calculate the parameter and residual vectors as follows:

$$
\begin{gathered}
\hat{\boldsymbol{X}}^{(k)}=\left(\boldsymbol{A}^{\mathrm{T}} \overline{\boldsymbol{P}}^{(k)} \boldsymbol{A}\right)^{-1} \boldsymbol{A}^{\mathrm{T}} \overline{\boldsymbol{P}}^{(k)} \boldsymbol{L} \\
\boldsymbol{V}^{(k)}=\boldsymbol{A} \hat{\boldsymbol{X}}^{(k)}-\boldsymbol{L}
\end{gathered}
$$

Step 3: Compute standardized residuals as below:

$$
\begin{gathered}
\sigma_{0}^{(k)}=1.4826 * \underset{i=1}{m e d}\left(\left|v_{i}^{(k)} / \sqrt{q v_{i}}\right|\right) \\
\widetilde{v}_{i}^{(k)}=v_{i}^{(k)} /\left(\sigma_{0}^{(k)} \sqrt{q v_{i}}\right)
\end{gathered}
$$

Step 4: Calculate weight factors by substituting Equations (17) into (10) and then update the equivalent weight: $\bar{p}_{i}^{(k+1)}=p_{i} w_{i i}$.

Step 5: Increase $k=k+1$, repeat Step 2 to 4 until $\left\|\hat{\boldsymbol{X}}^{(k+1)}-\hat{\boldsymbol{X}}^{(k)}\right\|<\varepsilon_{0}$.

After the parameters are estimated, we can assess the precision requirements of the solution for robust estimation and the corresponding variance factor of the unit weight is estimated as:

$$
\hat{\sigma}_{0}^{2}=\frac{\boldsymbol{V}^{T} \overline{\boldsymbol{P}} \boldsymbol{V}}{m-n-n 0}
$$

where $n 0$ represents the number of observations that contain gross errors where the weight factors are equal to 0.

Thus, the covariance matrix of the estimates can be obtained via variance propagation to Equation (8) as:

$$
D_{\hat{\mathbf{X}}}=\hat{\sigma}_{0}^{2}\left(\boldsymbol{A}^{\mathrm{T}} \overline{\boldsymbol{P}} \boldsymbol{A}\right)^{-1}
$$




\subsection{Expanded Forms of the Involved Matrices and a Test Case}

A large number of observations consume a lot of memory when constructing the matrices $\boldsymbol{P}$ and $\overline{\boldsymbol{P}}$. As a result, the computational burden is too large; sometimes calculation failure may occur.

In order to solve this problem, we make full use of matrix calculation principles. Since we assume that $\boldsymbol{P}$ and $\overline{\boldsymbol{P}}$ are diagonal matrices, Equation (12) can be written as:

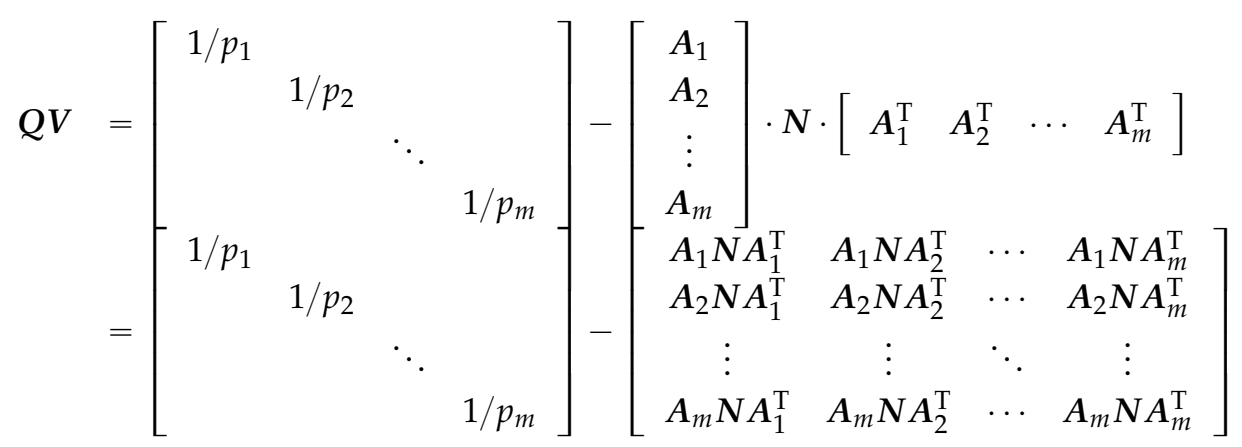

where $A_{i}$ represents the $i$ th row of matrix $A$. The $i$ th diagonal element of $Q v\left(q v_{i}\right)$ therefore can be expressed as the following:

$$
q v_{i}=1 / p_{i}-A_{i} \boldsymbol{N}^{-1} \boldsymbol{A}_{i}^{\mathrm{T}}
$$

The matrix $N$ in Equations (6), (12) and (21) can be expanded as below:

$$
\boldsymbol{N}=\boldsymbol{A}^{\mathrm{T}} \boldsymbol{P} \boldsymbol{A}=\left[\begin{array}{ccccc}
\sum_{k=1}^{m} A_{k 1} p_{k} A_{k 1} & \sum_{k=1}^{m} A_{k 1} p_{k} A_{k 2} & \cdots & \sum_{k=1}^{m} A_{k 1} p_{k} A_{k n} \\
\sum_{k=1}^{m} A_{k 2} p_{k} A_{k 1} & \sum_{k=1}^{m} A_{k 2} p_{k} A_{k 2} & \cdots & \sum_{k=1}^{m} A_{k 2} p_{k} A_{k n} \\
\vdots & \vdots & \ddots & \vdots \\
\sum_{k=1}^{m} A_{k n} p_{k} A_{k 1} & \sum_{k=1}^{m} A_{k n} p_{k} A_{k 2} & \cdots & \sum_{k=1}^{m} A_{k n} p_{k} A_{k n}
\end{array}\right]
$$

In addition, the matrix $C$ in Equation (6) can be expanded as:

$$
\boldsymbol{C}=\boldsymbol{A}^{\mathrm{T}} \boldsymbol{P} \boldsymbol{L}=\left[\begin{array}{c}
\sum_{k=1}^{m} A_{k 1} p_{k} L_{k} \\
\sum_{k=1}^{m} A_{k 2} p_{k} L_{k} \\
\vdots \\
\sum_{k=1}^{m} A_{k n} p_{k} L_{k}
\end{array}\right]
$$

Thus, the any one element of $N$ is summarized as:

$$
N_{i j}=\sum_{k=1}^{m} A_{k i} p_{k} A_{k j},(i=1, \cdots n, j=1, \cdots n)
$$

The ith element of $C$ is written as:

$$
C_{i}=\sum_{k=1}^{m} A_{k i} p_{k} L_{k},(i=1, \cdots n)
$$

The matrices $\boldsymbol{A}^{\mathrm{T}} \overline{\boldsymbol{P}} \boldsymbol{A}$ and $\boldsymbol{A}^{\mathrm{T}} \overline{\boldsymbol{P}} \boldsymbol{L}$ have similar expanded forms with $\boldsymbol{N}$ and $\boldsymbol{C}$, respectively. We can present them as follows:

$$
\left(A^{\mathrm{T}} \overline{\boldsymbol{P}} \boldsymbol{A}\right)_{i j}=\sum_{k=1}^{m} A_{k i} \bar{p}_{k} A_{k j},(i=1, \cdots n, j=1, \cdots n)
$$




$$
\left(\boldsymbol{A}^{\mathrm{T}} \overline{\boldsymbol{P}} \boldsymbol{L}\right)_{i}=\sum_{k=1}^{m} A_{k i} \bar{p}_{k} L_{k},(i=1, \cdots n)
$$

The quadratic sum $\boldsymbol{V}^{\mathrm{T}} \overline{\boldsymbol{P}} \boldsymbol{V}$ in Equation (18) can also be written as:

$$
\boldsymbol{V}^{\mathrm{T}} \overline{\boldsymbol{P}} \boldsymbol{V}=\sum_{i=1}^{m} \bar{P}_{i} v_{i}^{2}
$$

Based on these expanded formulas, there is no need to program the matrices $\boldsymbol{P}$ and $\overline{\boldsymbol{P}}$ and unnecessary calculations are avoided. The robust estimation method can easily be applied in cases with a large number of observations. Especially in instances when interferograms are at high resolution and with good coherence, the high density of PS pixels results in higher computational efficiency. Therefore, we can estimate the phase-elevation ratio $K^{\prime}$ locally over each block by applying the expanded forms of the robust estimation method. According to the rewritten linear model (Equation (2)), the corresponding matrices can be constructed as the following:

$$
\Delta \phi_{\text {trop }, f i l t, i}+v_{i}=K^{\prime} h_{f i l t, i}+\phi_{c}
$$

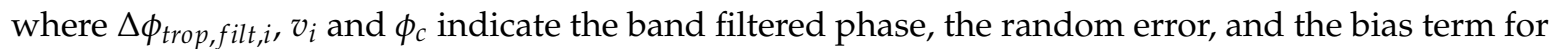
$i$ th PS point on a local block, respectively. In the application of our robust estimation method to solve this linear model, matrices in Equation (23) are constructed as:

$$
\boldsymbol{A}=\left[\begin{array}{cc}
h_{f i l t, 1} & 1 \\
h_{f i l t, 2} & 1 \\
\vdots & \vdots \\
h_{f i l t, N} & 1
\end{array}\right] \boldsymbol{L}=\left[\begin{array}{c}
\Delta \phi_{\text {trop,filt,1 }} \\
\Delta \phi_{\text {trop,filt,2 }} \\
\vdots \\
\Delta \phi_{\text {trop,filt,N }}
\end{array}\right] \hat{\boldsymbol{X}}=\left[\begin{array}{c}
K^{\prime} \\
\phi_{c}
\end{array}\right] \boldsymbol{P}=\boldsymbol{I}_{N}
$$

where $\boldsymbol{I}_{N}$ represents the $N \times N$ unit matrix and the $\mathrm{N}$ indicates the number of PS on local block.

In order to verify the feasibility and advantages of our robust estimation method, we tested the approach on InSAR data from an experimental region about $100 \mathrm{~km}^{2}$ in size, the dataset is shown in Table 1. In the experimental region A (red rectangle in Figure 1), a small-scale deformation area located at Pomona appears to reflect water withdrawal. We estimated the local phase-elevation ratio assuming the linear model (Equation (1)) with conventional least squares method and the robust estimation method, respectively. Table 3 shows the improvement in the standard deviation values after applying our robust estimation method. These results suggest that this robust estimation method yields the phase-elevation ratio more robustly and reliably.

Table 3. Improvement of standard deviation (STD) by the robust estimation.

\begin{tabular}{cccc}
\hline Ifg Index & Improvement STD (\%) & Ifg Index & Improvement STD (\%) \\
\hline 1 & 23.7 & 11 & 6.8 \\
2 & 5.4 & 12 & 2.4 \\
3 & 0.2 & 13 & 13.1 \\
4 & 4.2 & 14 & 3.0 \\
5 & 3.7 & 15 & 8.4 \\
6 & 1.6 & 16 & 6.0 \\
7 & 14.4 & 17 & 14.0 \\
8 & 2.4 & 18 & 12.8 \\
9 & 0.1 & 19 & 28.7 \\
\hline
\end{tabular}

\subsection{The Multi-Weighted Phase-Elevation Ratio for PS}

Our Robust Multi-Weighted (RMW) method splits the study region into multiple blocks (40 in the study), which are increasing bottom up and starting in the lower left corner. To ensure adjacent consistence, these blocks within a tropospheric region constrain the phase-elevation ratio estimation 
with a 50 percent overlap. Then, all local ratios are multiply weighted and interpolated to all PS points for a full interferogram. The weight function is constructed using the block uncertainty of the estimate and the distance from the block centers to each PS point. Equations (31)-(33) show the form of the weight combination and final derived phase-elevation ratios for all PS points.

$$
\begin{aligned}
& S=\left[\begin{array}{cccc}
s_{1}^{-1} / \sum_{i=1}^{n} s_{i}^{-1} & s_{2}^{-1} / \sum_{i=1}^{n} s_{i}^{-1} & \cdots & s_{n}^{-1} / \sum_{i=1}^{n} s_{i}^{-1} \\
s_{1}^{-1} / \sum_{i=1}^{n} s_{i}^{-1} & s_{2}^{-1} / \sum_{i=1}^{n} s_{i}^{-1} & \cdots & s_{n}^{-1} / \sum_{i=1}^{n} s_{i}^{-1} \\
\vdots & \vdots & \ddots & \vdots \\
s_{1}^{-1} / \sum_{i=1}^{n} s_{i}^{-1} & s_{2}^{-1} / \sum_{i=1}^{n} s_{i}^{-1} & \cdots & s_{n}^{-1} / \sum_{i=1}^{n} s_{i}^{-1}
\end{array}\right]_{N \times n} \\
& W_{j, k}=G_{j, k} \cdot S_{j, k}(j=1,2 \cdots N, k=1,2 \cdots n) \\
& K_{N \times 1}^{\prime}=\left[\begin{array}{cccc}
W_{1,1} / \sum_{i=1}^{n} W_{1, i} & W_{1,2} / \sum_{i=1}^{n} W_{1, \mathrm{i}} & \cdots & W_{1, n} / \sum_{i=1}^{n} W_{1, \mathrm{i}} \\
W_{2,1} / \sum_{i=1}^{n} W_{2, i} & W_{2,2} / \sum_{i=1}^{n} W_{2, i} & \cdots & W_{2, \mathrm{n}} / \sum_{i=1}^{n} W_{2, i} \\
\vdots & \vdots & \ddots & \vdots \\
W_{\mathrm{N}, 1} / \sum_{i=1}^{n} W_{N, i} & W_{\mathrm{N}, 1} / \sum_{i=1}^{n} W_{N, i} & \cdots & W_{\mathrm{N}, \mathrm{n}} / \sum_{i=1}^{n} W_{N, i}
\end{array}\right]_{N \times n}\left[\begin{array}{c}
K_{1}^{\prime} \\
K_{2}^{\prime} \\
\vdots \\
K_{n}^{\prime}
\end{array}\right]_{n \times 1}
\end{aligned}
$$

where $S$ and $G$ represent the reformed weights of the standard deviation (Equation (19)) and Gaussian distribution based on the distance, respectively. $s_{i}$ is the $i$ th standard deviation of local phase-elevation ratio over the $i$ th block.
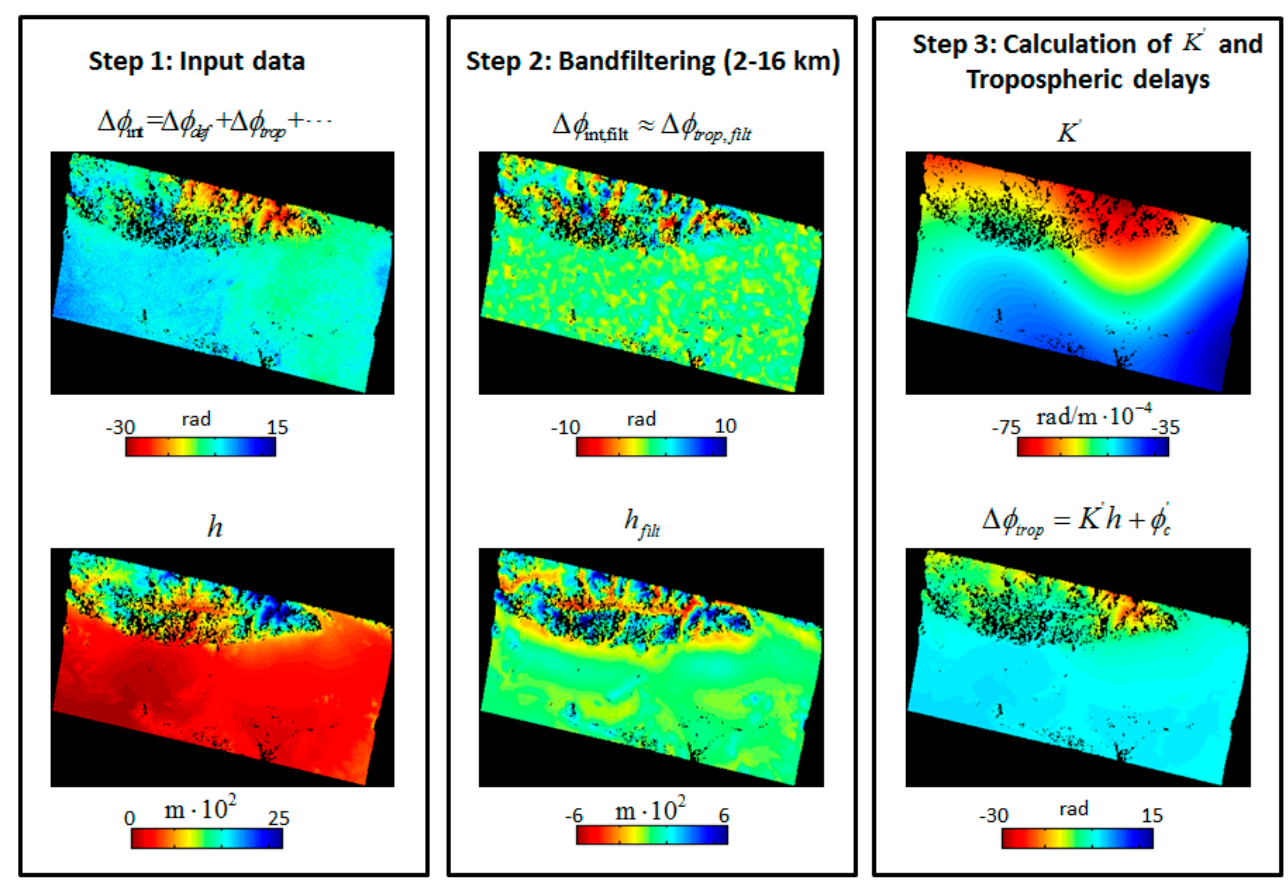

Figure 2. Tropospheric delay estimated using the RMW method for the interferogram created from images collected on 12 July 2008 and 18 April 2009. Step 1: the original interferometric phase $\Delta \phi_{\text {int }}$ above and the elevation $h$ below were derived from the SRTM DEM. Step 2: the band filtering in the 2-16 km spatial wavelength. Step 3: a spatial map of $K^{\prime}$ was acquired after local robust estimation for each block and subsequent extrapolation using multi-weights for all PS points. The final tropospheric delays (Step 3, lower figure) were obtained using the rewritten linear model (Equation (3)). 
The multi-weight $W$ is a $N \times n$ matrix. $K^{\prime}$ is the final derived phase-elevation ratio for all PS points. $N$ is the number of PS points and $\mathrm{n}$ is the number of blocks for the whole interferogram. Figure 2 shows a step-by-step example of the RMW method for an interferogram spanning 12 July 2008 to 18 April 2009.

\section{Results and Discussion}

\subsection{Time Series InSAR Results}

We used StaMPS software to perform InSAR time series analysis and to estimate DEM errors. After PS selection and DEM error correction, the interferograms were unwrapped in three dimensions [24]. The unwrapped time series interferograms after the DEM errors were removed are shown in Figure 3a. The signals in these unwrapped interferograms consist of the contribution of the ground deformation, which we are interested in understanding and the tropospheric phase delay that must be removed. Note that the spatial-temporal filtering in StaMPS is not used to estimate the tropospheric delay. Instead we used our RMW method to calculate the delays for individual interferograms.
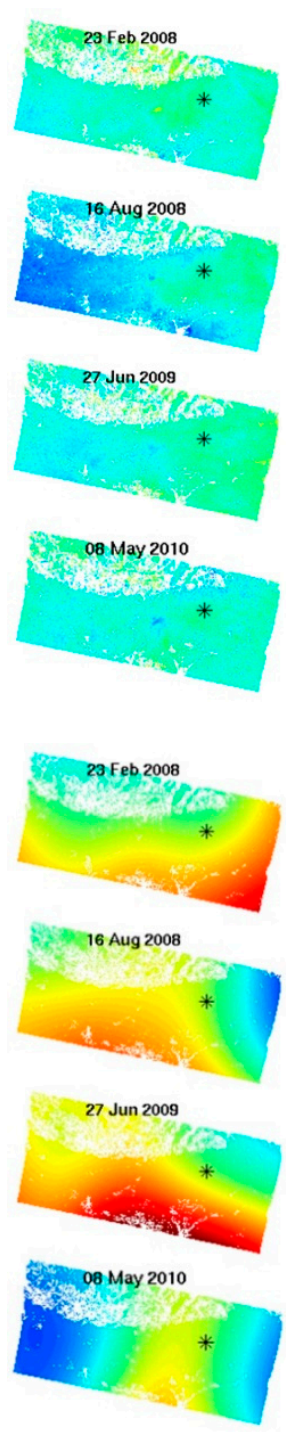
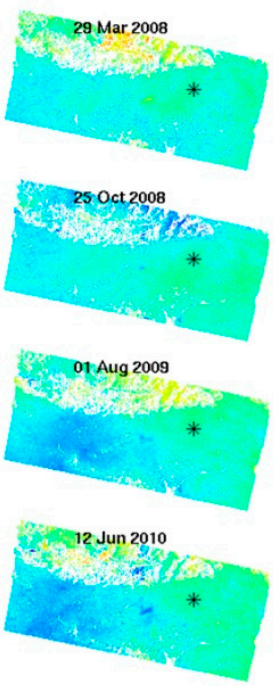

(a) Unwrapped interferograms corrected for DEM errors
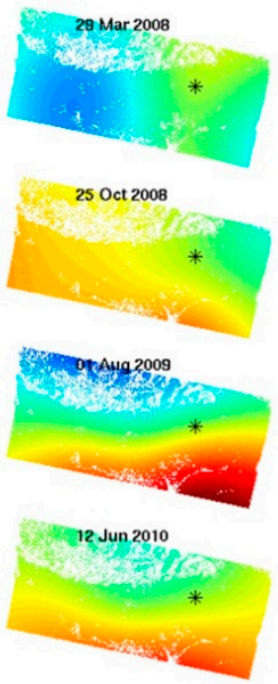

(b) Spatial maps of $K^{\prime}$ using the RMW method
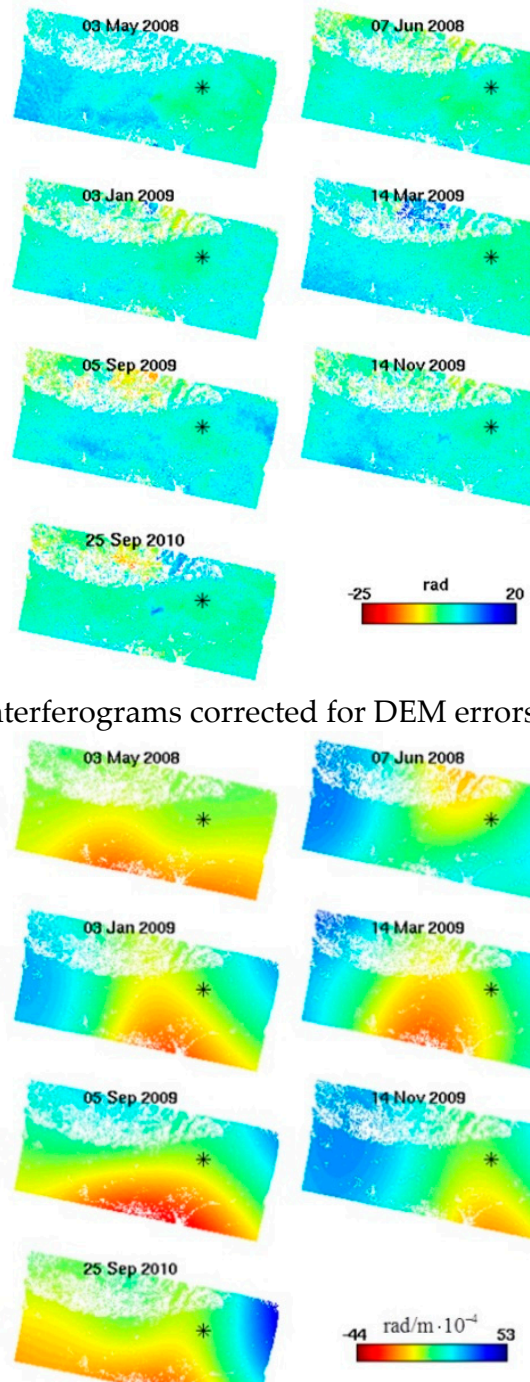
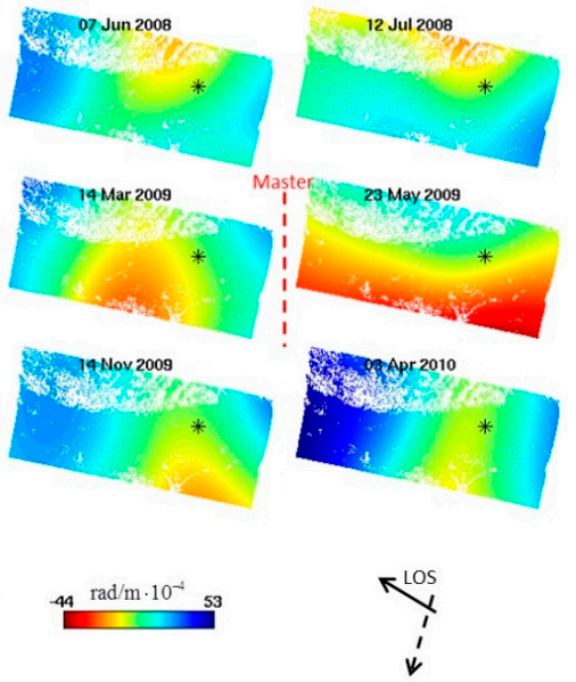

Figure 3. Cont. 

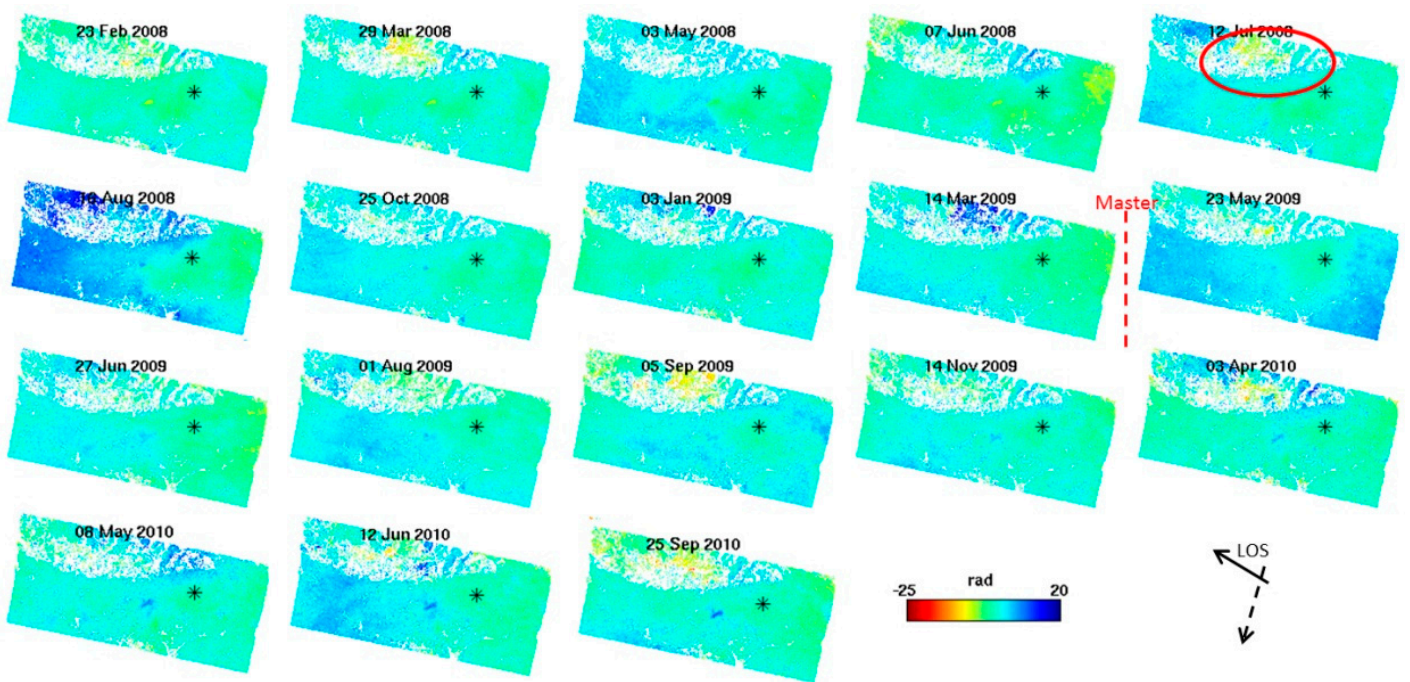

(c) Unwrapped interferograms corrected for DEM errors and estimated tropospheric phase delays

Figure 3. (a) Unwrapped time series interferograms corrected for DEM errors, containing tropospheric phase delays and deformation phases; (b) Spatial maps of $K^{\prime}$ estimated by our RMW method; (c) Final unwrapped differential interferograms corrected for DEM errors and the tropospheric phase delays using our RMW method. The master date is 18 April 2009 and the asterisk represents the center of the reference area with a $300-\mathrm{m}$ radius. A change of $2 \pi$ radians corresponds to a $28 \mathrm{~mm}$ displacement in the LOS direction.

The spatial map of $K^{\prime}$ estimated from our RMW method is shown in Figure 3b. Figure 3c shows the interferograms that the tropospheric phase delay estimated by our RMW method has been subtracted. Finally, the mean-velocity map over the study area was obtained (Figure 4). Subsidence in the Pomona Basin can be observed in the unwrapped interfergrams (Figure 3a) and the mean-velocity map (Figure 4).

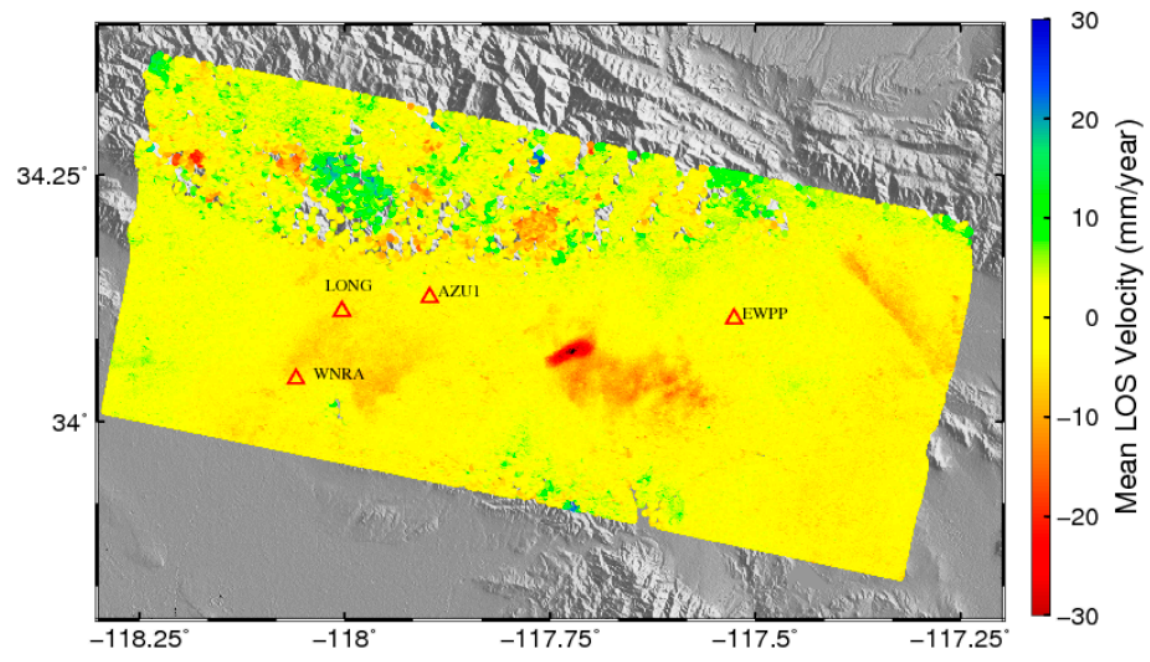

Figure 4. Mean displacement rates (mm/year) of PS in the Line of Sight (LOS) direction after removal of DEM errors and tropospheric phase delays in the study area (The red triangles represent the locations of GPS sites and the background is the SRTM DEM).

Those interferograms in Figure 3a without tropospheric delay correction contain both ground deformation and tropospheric phase delay. We found that the phase delay partly varies with 
topography. For example, the interferogram for 12 July 2008 shows strong spatial correlation with surface topography. As Figure $3 \mathrm{c}$ shows, these delays were significantly mitigated after correction of the interferogram using our RMW method. We validated our RMW method by comparing with the conventional linear method. The linear method shown in Equation (1) assumes a simple phase-topography relationship for individual interferograms and therefore does not allow for spatially variable tropospheric delay. However, we were able to account for the spatial variation of tropospheric delay by applying the RMW method, as can be seen from the spatial variation maps of $K^{\prime}$ shown in Figure 3b. Here, we compared the mitigation results of the RMW method with the unwrapped interferograms, expecting a large reduction in local correlation to topography. In order to find a clear phase-topography relationship, we excluded pixels at an altitude below $800 \mathrm{~m}$ because of the deformation signal existing in the Pomona Basin. In this region, the unwrapped phases are variable and discontinuous in some areas and therefore the tropospheric signals are contaminated by deformation signals. These can be observed in the 8 May 2010, 12 June 2010, and 25 September 2010 interferograms shown in Figure 3a. It is still important to remove the contributions from deformation -contaminated bands over the flat area in Pomona Basin, especially in the area A (Figure 1) and its surrounding regions. The variable and discontinuous phases in the interferograms demonstrate tropospheric change and deformation mask influences. Therefore, a robust and spatially varying tropospheric delay correction is necessary.

On average, we found a strong local relationship $\left|k_{\Delta \varphi}\right|$ of $3.9 \mathrm{rad} / \mathrm{km}(\sim 1.7 \mathrm{~cm} / \mathrm{km})$ for our 18 interferograms before the tropospheric correction (the green points shown in Figure 5). After the linear correction method (blue points), we found an average reduction in the local correlation to topography of $2.0 \mathrm{rad} / \mathrm{km}(\sim 0.9 \mathrm{~cm} / \mathrm{km})$. However, the local correlation increased at an average value of $1.3 \mathrm{rad} / \mathrm{km}(\sim 0.6 \mathrm{~cm} / \mathrm{km})$ in the 23 February 2008, 3 May 2008, 23 May 2009, 12 June 2010, and 25 September 2010 interferograms.

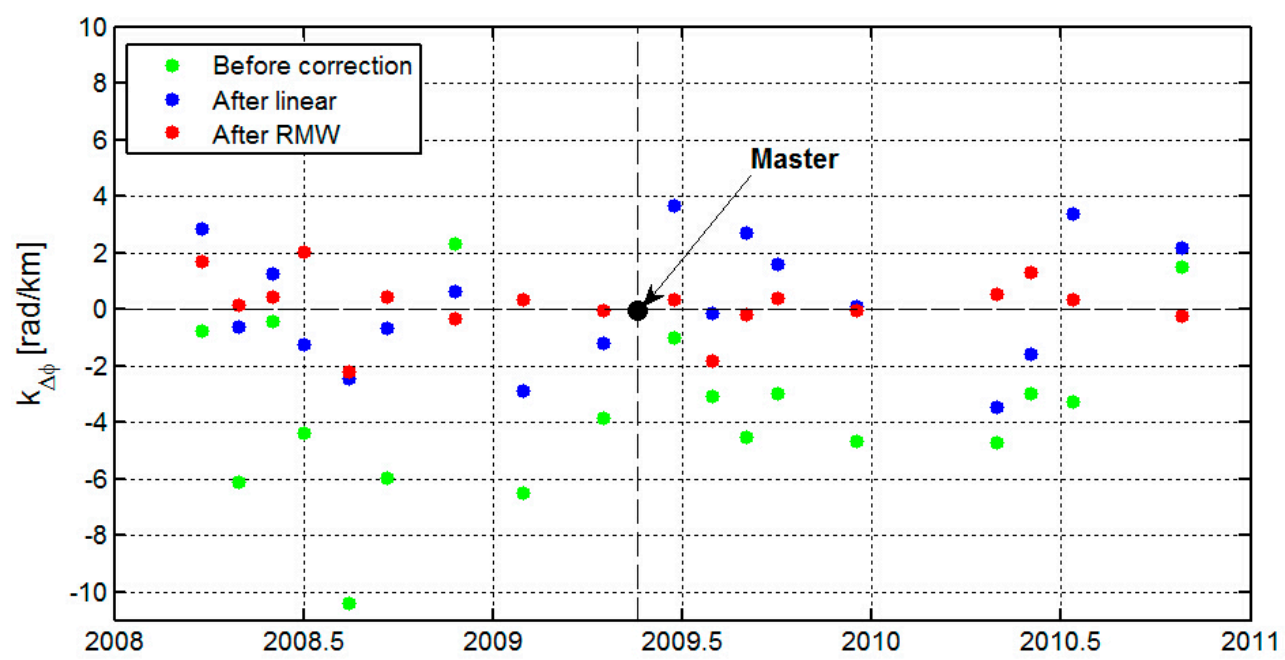

Figure 5. Comparing the local correlation $k_{\Delta \phi}$ between the interferogram $\Delta \phi$ and topography $h$. Only pixels with altitude above $800 \mathrm{~m}$ are used. Where $\Delta \phi=k_{\Delta \phi} h+\phi_{c}$, then $k_{\Delta \phi}$ is estimated before (green points) and after correction for the tropospheric delays, using the conventional linear method (blue points) and the RMW method (red points). The constant $\phi_{c}$ represents an overall offset and was applied to the whole interferogram.

After treatment with the RMW method (red points), we found an average reduction in local correlation with topography of $3.1 \mathrm{rad} / \mathrm{km}(\sim 1.4 \mathrm{~cm} / \mathrm{km})$, about three fourth of the signal, with the increase only for 23 February $2008(0.9 \mathrm{rad} / \mathrm{km}$ or $0.4 \mathrm{~cm} / \mathrm{km})$ interferogram. The strongest reductions were observed in the 12 July $2008(8.2 \mathrm{rad} / \mathrm{km}$ or $3.7 \mathrm{~cm} / \mathrm{km})$ and 3 January $2009(6.2 \mathrm{rad} / \mathrm{km}$ or $2.8 \mathrm{~cm} / \mathrm{km}$ ) interferograms. Figure 6 shows the two interferograms with the strongest reduction 
results before and after the tropospheric corrections. These two interferograms show the reductions in local correlation with topography of $8.0 \mathrm{rad} / \mathrm{km}(\sim 3.6 \mathrm{~cm} / \mathrm{km})$ and $3.6 \mathrm{rad} / \mathrm{km}(\sim 1.6 \mathrm{~cm} / \mathrm{km})$ using the linear method. The RMW method however performs better, with reductions of $8.2 \mathrm{rad} / \mathrm{km}$ $(3.7 \mathrm{~cm} / \mathrm{km})$ and $6.2 \mathrm{rad} / \mathrm{km}(2.8 \mathrm{~cm} / \mathrm{km})$. These comparative results show that the RMW method outperforms the conventional linear method. Additionally, taking the 23 February 2008 interferogram as an example, the local correlation increased $2.1 \mathrm{rad} / \mathrm{km}(\sim 0.9 \mathrm{~cm} / \mathrm{km})$ while the correlation based on the full interferogram decreased $3.6 \mathrm{rad} / \mathrm{km}(\sim 1.6 \mathrm{~cm} / \mathrm{km})$ after the linear correction. The increase in local correlation was due to the spatial variation of the troposphere, which cannot be captured using the linear method. Thus, the linear method estimated the phase-elevation ratio by a conventional LS method based on the whole interferogram and did not account for inconsistent filter bands and spatially variable tropospheric delays.
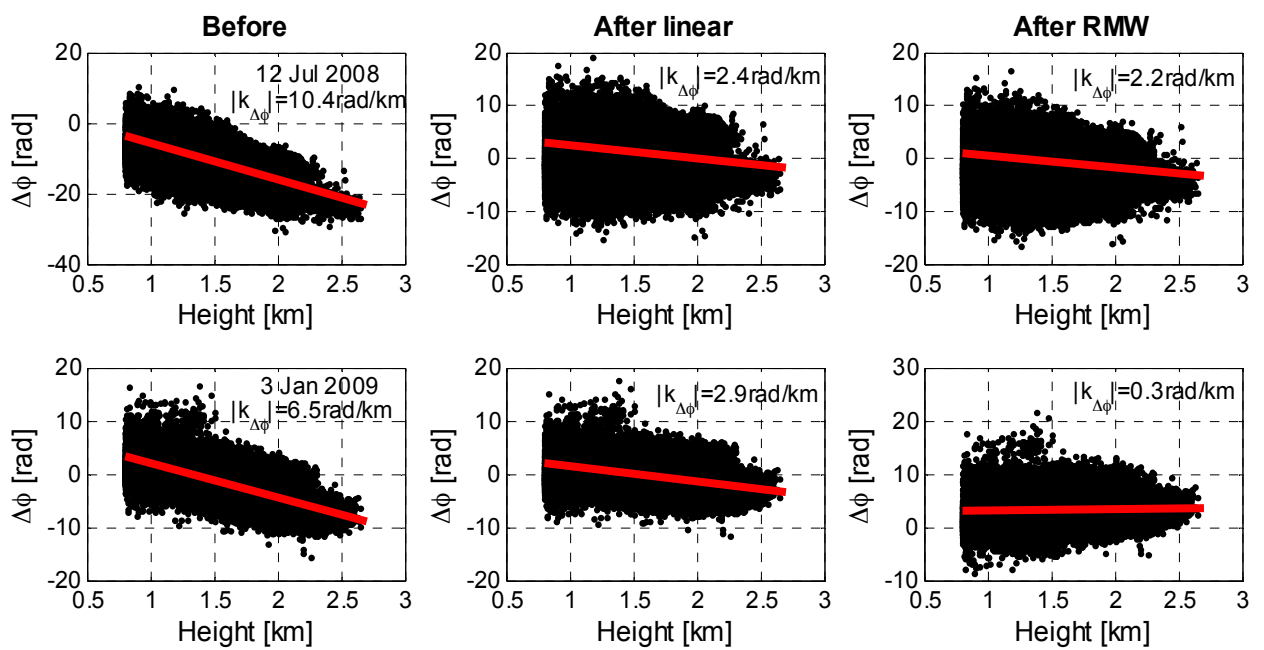

Figure 6. Scatterplots of the local correlation between interferograms and topography. A comparison of the estimated ratio $k_{\Delta \varphi}$ (red solid line) before and after correction for tropospheric delays using the linear and RMW methods for the 12 July 2008 and 3 January 2009 interferograms.

We further tested the advantages of our RMW method by splitting the interferograms into 28 blocks with different terrain patterns. Each block covers about $100 \mathrm{~km}^{2}$ containing mountain areas, basin areas, or both. We sampled the phases at the center of each block to examine the correlations between the original and the corrected phases, as shown in Figure 7. On average, we found a reduction (above zero) in local correlation with topography of $1.3 \mathrm{rad} / \mathrm{km}(\sim 0.6 \mathrm{~cm} / \mathrm{km})$ except for the 3 May 2008 and 25 September 2010 interferograms after the linear method correction. After RMW correction, the local correlation decreased with an average value of $1.5 \mathrm{rad} / \mathrm{km}(\sim 0.7 \mathrm{~cm} / \mathrm{km})$ for 17 out of 18 interferograms. The RMW method also performed better compared to the linear method with better reductions for 13 out of the total 18 interferograms.

Figure 8 shows the two largest differences of average $\Delta\left|k_{\Delta \phi}\right|$ between the two methods. For the 23 February 2008 interferogram (Figure 8a), we found that the RMW method decreased correlation with the topography to an average of $2.2 \mathrm{rad} / \mathrm{km}(\sim 1.0 \mathrm{~cm} / \mathrm{km}), 0.6 \mathrm{rad} / \mathrm{km}(\sim 0.3 \mathrm{~cm} / \mathrm{km})$ an improvement over the linear method. For the RMW method, 21 blocks had an average reduction of $3.6 \mathrm{rad} / \mathrm{km}$ $(\sim 1.6 \mathrm{~cm} / \mathrm{km})$; while for other blocks, an average increase (below zero) of $2.0 \mathrm{rad} / \mathrm{km}(\sim 0.9 \mathrm{~cm} / \mathrm{km}) \mathrm{was}$ observed. For the linear method, 20 blocks had an average reduction of $3.3 \mathrm{rad} / \mathrm{km}(1.5 \mathrm{~cm} / \mathrm{km})$ and an average increase of $2.8 \mathrm{rad} / \mathrm{km}(\sim 1.3 \mathrm{~cm} / \mathrm{km})$, and less efficient than the results from our RMW method. For the 14 March 2009 interferogram (Figure 8b), the RMW method generally under-performed the linear method, the average increase was only $1.8 \mathrm{rad} / \mathrm{km}(\sim 0.8 \mathrm{~cm} / \mathrm{km})$ while for the linear method the increase was $2.6 \mathrm{rad} / \mathrm{km}(\sim 1.2 \mathrm{~cm} / \mathrm{km})$. As the RMW method is applied locally, we found that it is more subject to contamination from various tropospheric delay components present at different spatial 
scales. This leads to a biased estimation of phase- elevation ratios with an average value of $0.4 \mathrm{rad} / \mathrm{km}$ $(\sim 0.2 \mathrm{~cm} / \mathrm{km})$ larger than the linear method. However, the impact of turbulence on the linear method appears less severe than for the RMW method. Due to the spatially variable estimation in the RMW method, the average standard deviation of $\Delta\left|k_{\Delta \phi}\right|$ for all interferograms was $0.2 \mathrm{rad} / \mathrm{km}$ larger than the linear method, as can be seen from the variation in the spatial maps of $\Delta\left|k_{\Delta \phi}\right|$ shown in Figure 8. The RMW method accounts for spatial variation by applying multi-weighted phase-elevation ratios robustly estimated from reliable band-filtered data on 40 blocks of half overlaps.

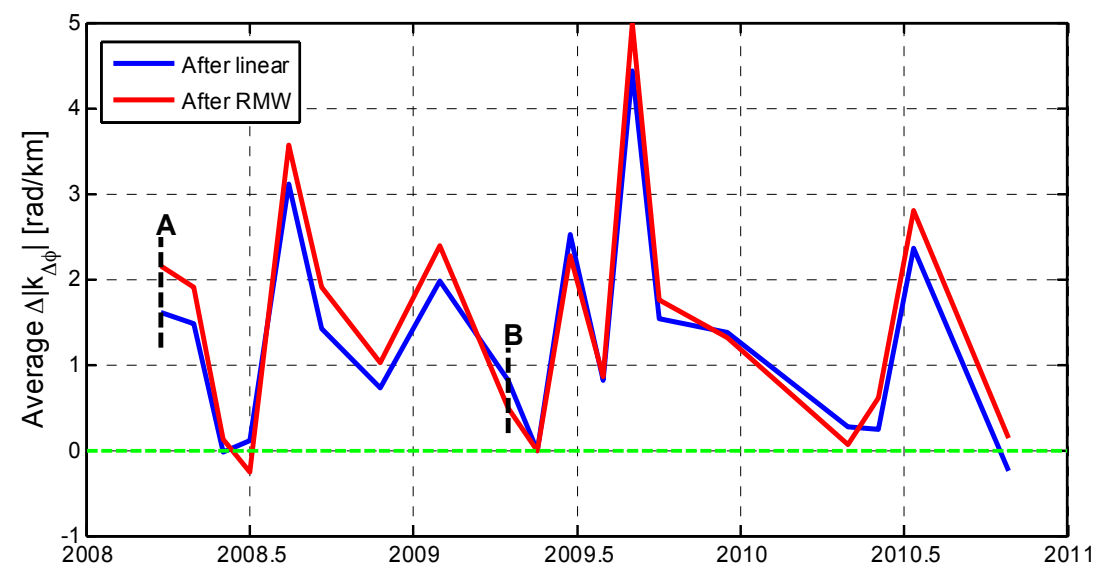

Figure 7. The difference value $\Delta\left|k_{\Delta \phi}\right|$ indicates a reduction or increase in local correlation with topography before and after tropospheric correction. This graph shows a comparison of the average $\Delta\left|k_{\Delta \phi}\right|$ in the center of 28 blocks for the corresponding interferogram after the correction for the linear (blue solid line) and RMW methods (red solid line). A comparison of A and B indicated by dashed black lines are specifically shown in Figure 8.

(a)

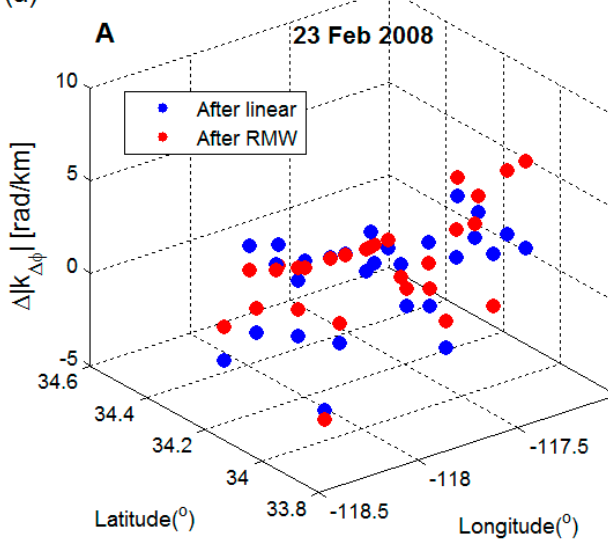

(b)

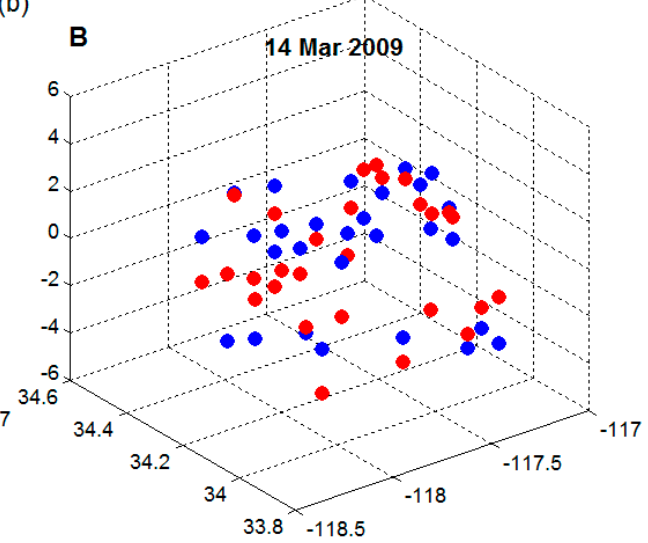

Figure 8. Comparison of the variation in the spatial spots of estimation $\Delta\left|k_{\Delta \phi}\right|$ after correction using the linear (blue solid points) and RMW methods (red solid points) for each block. The two examples; the (A) 23 February 2008 and (B) 14 March 2009 interferograms, show the largest differences of average $\Delta\left|k_{\Delta \phi}\right|$. Blocks cut across mountainous areas, basin areas, or both in segments of about $10 \mathrm{~km}$.

In general, the band-pass components usually display a clearly linear relationship between phase and topography, unlike the high-pass and low-pass components. The high pass and low pass components are therefore excluded from the estimation of phase-elevation ratios. The bandwidth range is limited by the resolution of the data and spatial extent of our study region. We performed a statistical comparison of our final performance results using multiple spatial bands. These results show that spatial bands on the $2-4 \mathrm{~km}, 4-8 \mathrm{~km}, 8-16 \mathrm{~km}, 2-8 \mathrm{~km}$ and 2-32 km wavelengths have an average 
reduction in the local correlation with topography of $1.2 \mathrm{rad} / \mathrm{km}(\sim 0.5 \mathrm{~cm} / \mathrm{km})$ with $0.1 \mathrm{rad} / \mathrm{km}$ $(\sim 0.1 \mathrm{~cm} / \mathrm{km})$ fluctuation. The $2-16 \mathrm{~km}$ spatial band showed an average reduction in the value for local correlation to topography of $1.5 \mathrm{rad} / \mathrm{km}(\sim 0.7 \mathrm{~cm} / \mathrm{km})$. The $16-32 \mathrm{~km}$ bands performed less effectively, with an average reduction of $0.6 \mathrm{rad} / \mathrm{km}(\sim 0.3 \mathrm{~cm} / \mathrm{km})$. Thus, the $2-16 \mathrm{~km}$ spatial band was less sensitive to the other signals, such as deformation, turbulence and residual orbit errors. However, the $2-16 \mathrm{~km}$ spatial band cannot completely remove the inconsistent bands and could cause residual signals to leak into the estimated tropospheric delay. However, the RMW method can significantly mitigate the effects of contaminated filter bands, but does not always work well. In some regions, phase does not seem linearly related to topography due to multiple tectonic influences or other non-tectonic sources and the variability of the atmospheric circulation due to turbulent tropospheric delays.

In order to validate our results, we compared the time series of LOS displacements measured by GPS to displacements measured by InSAR. We used four GPS stations from the Southern California Integrated GPS Network (SCIGN) for our comparison. The North, East, and Up direction displacement from GPS were projected to LOS direction for comparison. In Figure 9, we show the time series plots of measurements from the four GPS stations and ground displacement as estimated from InSAR images. The black triangles in Figure 9 represent displacement as estimated from InSAR without tropospheric correction, and the red circles indicate the displacement where the tropospheric delay was mitigated using our proposed RMW method. Because the GPS stations are located on flat terrain, topographically correlated tropospheric effects are not significant. The RMS errors before tropospheric correction on GPS stations are WNRA (14.22) mm, LONG (18.55 mm), AZU1 (11.57 mm) and EWPP (7.65 mm), after correction the RMS error was reduced to $10.79 \mathrm{~mm}, 16.26 \mathrm{~mm}, 10.88 \mathrm{~mm}$ and $5.51 \mathrm{~mm}$, respectively. These comparisons support our argument that the proposed RMW method is quite effective for mitigating the topographically correlated tropospheric delay and thus enables the extraction of more reliable surface deformation information.
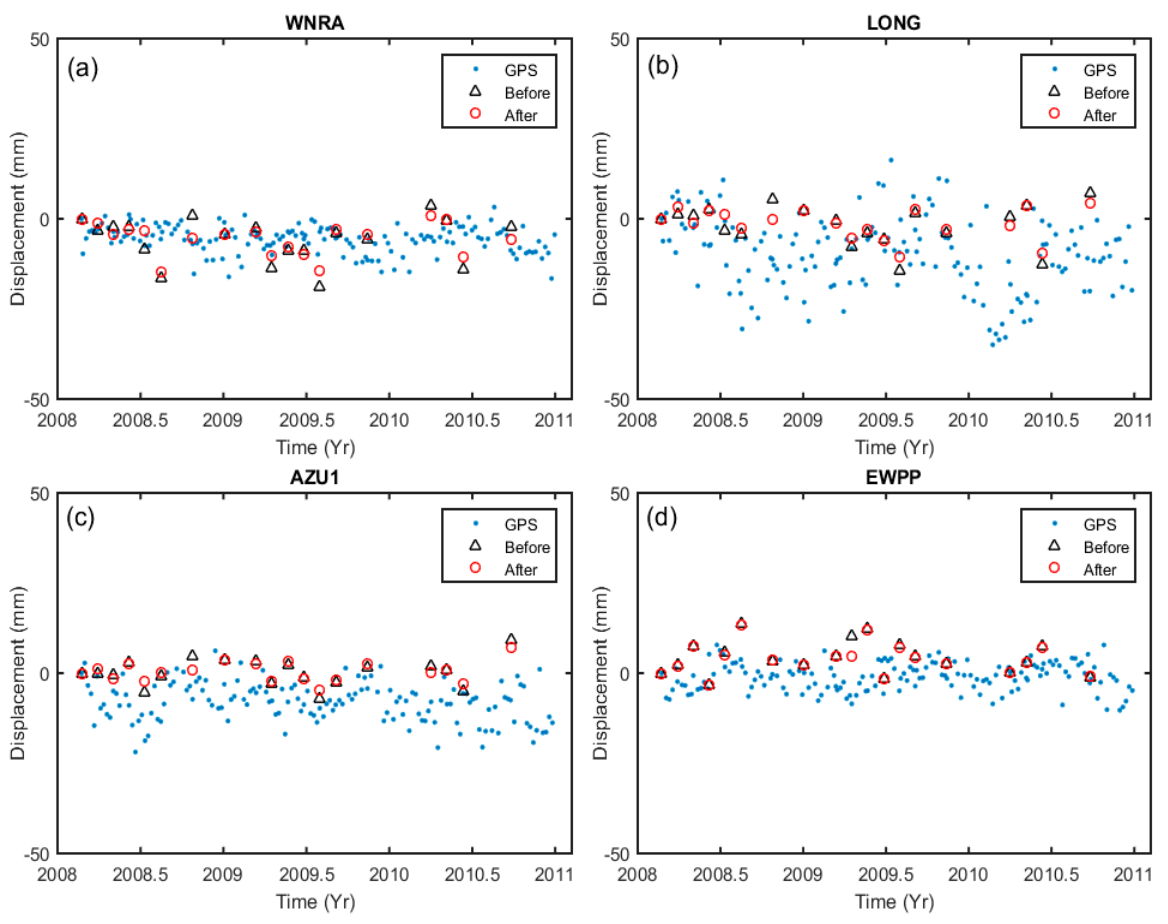

Figure 9. Shows a comparison of the LOS displacements measured by InSAR and GPS (blue points) at stations (a) WNRA; (b) LONG; (c) AZU1; and (d) EWPP. The black triangles and red circles represent displacements estimated from StaMPS with and without tropospheric correction, respectively.

\subsection{The Sensitivity of RMW Method to Orbital Ramp}

In this section, we will discuss how the orbital ramp influences the estimate of the phase-elevation ratio $k_{\Delta \phi}$. To do this, we compare our results with the $k_{\Delta \phi}$ values derived from the RMW method 
with the ramp retained and removed (Figure 10). For the full interferogram, on average we found a reduction in local correlation with topography of $1.0 \mathrm{rad} / \mathrm{km}(\sim 0.5 \mathrm{~cm} / \mathrm{km})$ for 11 interferograms after correction with our RMW method. Among these interferograms, the local correlation increased with an average value of $0.5 \mathrm{rad} / \mathrm{km}(0.2 \mathrm{~cm} / \mathrm{km})$ after the linear method correction. The RMW method performed more efficiently in comparison to the linear method with reductions of correlation in 10 out of 11 interferograms. To account for residual orbital errors, the original interferogram was corrected with a plane trend in the range and azimuth before applying our RMW method. Figure 10 illustrates that the local correlation estimated from the ramp-retained RMW method is almost the same as the local correlation estimated from the ramp-removed RMW method. This suggests that our RMW method is insensitive to the influence of the orbital ramp and therefore can estimate the tropospheric delay even when orbital errors or long wavelength deformation signals are present.

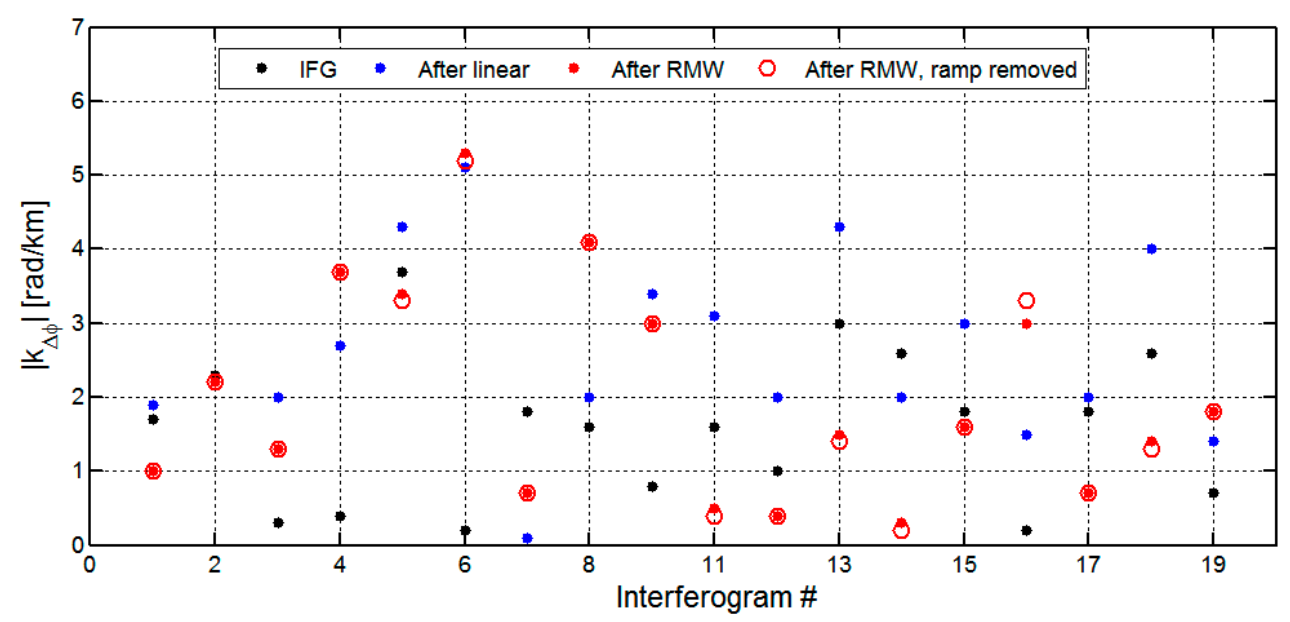

Figure 10. Comparison of the phase-elevation ratio $\left|k_{\Delta \phi}\right|$ for full interferograms after correction with the linear method (blue points), RMW method (red points) and with the ramp-removed RMW method (red circles). The comparative unwrapped interferograms (black points) were corrected for DEM and residual orbital errors, respectively.

\subsection{The Effects of Turbulent Delay}

We also considered how turbulence mixing in the interferogram influenced estimates of $k_{\Delta \phi}$. The tropospheric delay is considered as the sum of two components, stratified delay and turbulent delay. The stratified delay results from different vertical refractivity profiles during two SAR acquisitions, showing a strong correlation with topography. This applies to mountainous terrain only. Turbulence is an irregular and random motion, and dependent on the random characteristics of meteorological phenomena affected by flat as well as mountainous terrain. The focus of our study is to estimate the stratified delay that often dominates the tropospheric signal in an interferogram. The analysis in Section 4.2 shows that for most inteferograms, the RMW method is quite effective in mitigating topographically correlated tropospheric delays. However, some cases show very small improvements and the RMW method may even introduce atmospheric estimation error, leading to inaccurate information in the final deformation results (Figure 10).

We selected two interferograms with a wider coverage to test the effect of turbulence effects (the blue rectangle in Figure 1). We validated our results using the passive multispectral imager Medium-Resolution Imaging Spectrometer (MERIS) onboard the Envisat satellite [35]. MERIS -derived prediction is restricted to instances where the cloud coverage is less than $20 \%$ of the scene. At the scale of an interferogram, the spatial variations in pressure are usually small, typically at an order of magnitude of $1 \mathrm{hPa}$. 
IFG

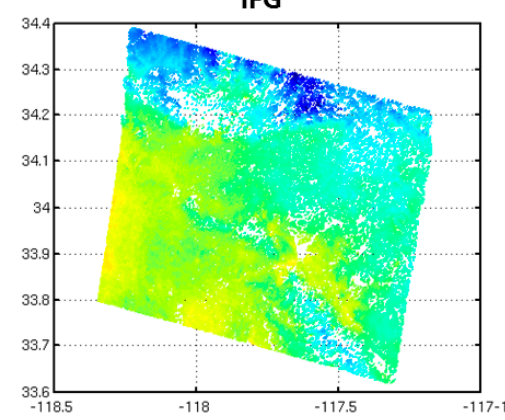

IFG

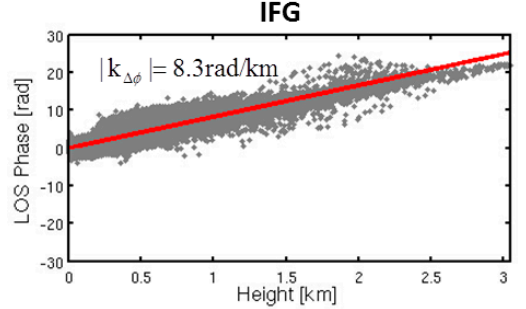

MERIS

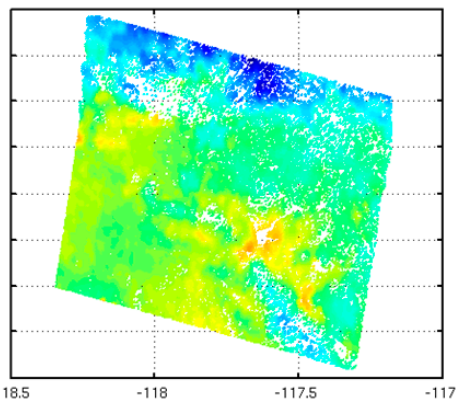

After MERIS

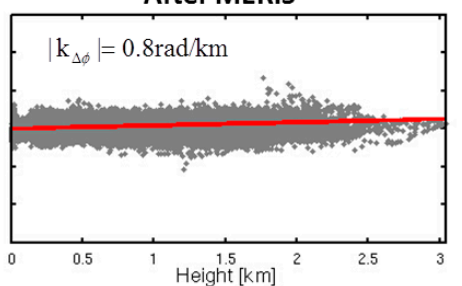

RMW

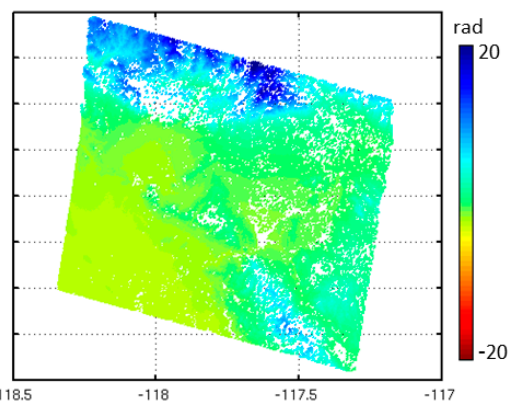

After RMW

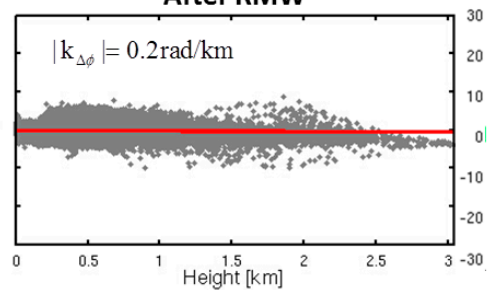

Figure 11. A comparison of the performance of the MERIS correction and the RMW method correction. A stratified dominant interferogram was generated using two SAR acquisitions on 16 August 2008 and 25 October 2008 by the Envisat satellite over California. The average $B_{\perp}$ is $272 \mathrm{~m}$. The original interferogram has been corrected for the residual orbital errors. The tropospheric delay has a strong linear relationship with elevation. The prediction of tropospheric delay using MERIS and the RMW method show a good agreement, with a difference in the standard deviation of $0.1 \mathrm{rad}$ along the LOS. The standard deviation of the residuals after correction using MERIS data was about $1.6 \mathrm{rad}$ and $1.7 \mathrm{rad}$ after correction with the RMW method. The standard deviation reduction after correction with the RMW method was about $55 \%$.

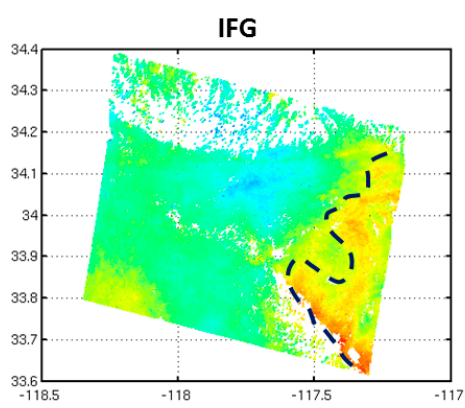

IFG

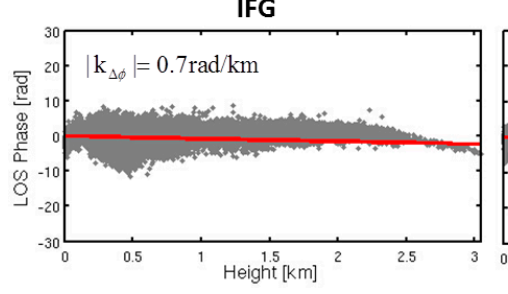

MERIS

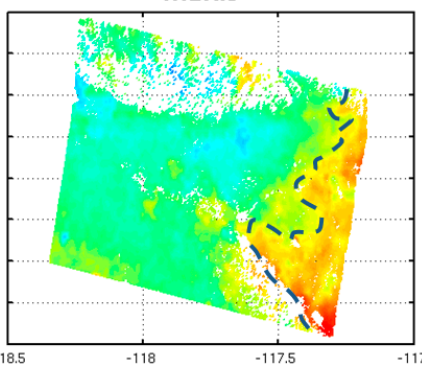

After MERIS

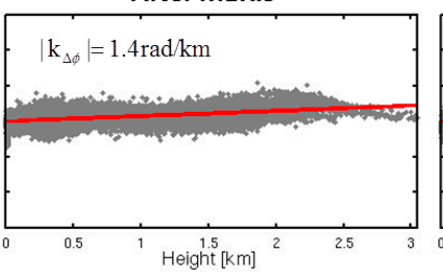

RMW

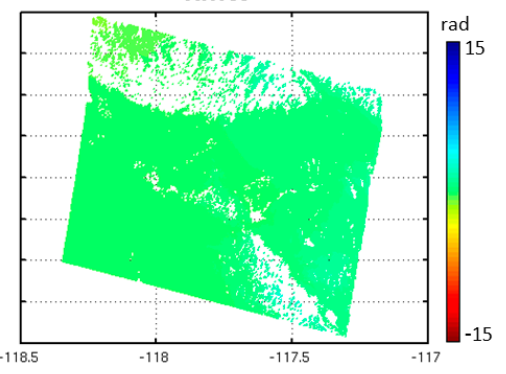

After RMW

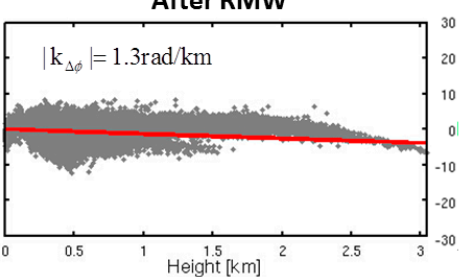

Figure 12. A comparison of the performance of the MERIS correction and the RMW method correction. A turbulent dominant interferogram was generated using two SAR acquisitions collected on 23 May 2009 and 27 June 2009. The average $B_{\perp}$ is $406 \mathrm{~m}$. The original interferogram was corrected for residual orbital errors. As shown, the troposphere delay is not linearly related to topography. The standard deviation reduced by about $42 \%$ after correction with MERIS while the standard deviation increased about $8 \%$ after correction with the RMW method. 
We excluded the hydrostatic component when we calculated the MERIS tropospheric delay. When the stratified delays dominate signals (Figure 11), the tropospheric delay shows a strong correlation with topography, this delay can be accurately estimated based on the RMW method. Hence, the tropospheric effects are significantly mitigated. When turbulent delay overwhelmed the interferogram (Figure 12), we found that both the original interferogram and the prediction of tropospheric delay did not appear in the correlation between the phase and topography. The RMW method cannot properly estimate such small-scale tropospheric signal, shown on the right side of the dashed line in Figure 12. Therefore, our proposed RMW method is not suitable for estimating significant turbulence mixing effects in interferograms.

\section{Conclusions}

To tackle the issue of contaminated and inconsistent bands in the processing of phase-based tropospheric delay correction, we propose a novel expanded form of the robust estimation method for larger spatial data sets, RMW. As the analysis of experimental results show, we take advantage of the $2-16 \mathrm{~km}$ band-filter to estimate the spatially variable phase-elevation ratio $K$ robustly; in a way that is relatively suitable and advantageous for areas with confounding processes. The method splits a region into multiple blocks (about $100 \mathrm{~km}^{2}$ in our study) and estimates the ratio $\mathrm{K}$ locally to resolve lateral variations in stratification over lager regions. The standard deviations derived by robust estimation combined with Gaussian weights were used to construct a multi-weighted factor function for spatially variable tropospheric correction. The multi-weighted factor function constructed with standard deviation simultaneously considers the robustness in the observation and structure spaces. The iterative calculation approach applied in the RMW method is relatively straightforward and efficient. In some regions of our study area, the proposed method was very effective when no other auxiliary and independent data was available.

We tested the RMW method over Southern California, where the mountainous areas and the flat area coexist with a small-scale deformation in the Pomona Basin. After correction, we found a better degree of reduction in the topographically correlated tropospheric signals than the conventional linear method, and an improved correlation between InSAR and GPS estimated surface displacements. We can mitigate bias in displacement rate estimates by robust estimated phases while using time series analysis in the differential interferograms. Experimental results also demonstrated that the RMW method is insensitive to orbital ramps. However, the differences between RMW method and conventional linear methods were relatively small in flat terrain areas. Our method is based on the same assumption made by earlier studies of a linear relationship between topography and phase; therefore some tropospheric phase components do not directly relate linearly to topography directly, given complex turbulent atmospheric delay effects and tectonic influences or effects stemming from other, non-tectonic sources. Therefore, in some cases, more comprehensive correction methods are required due to the complicated geological structure of the earth and the variability in the atmospheric circulation.

Acknowledgments: We greatly appreciated the financial supports from the National Natural Science Foundation of China (No. 41404028) and the National Basic Research Program of China (No. 2013CB733300).

Author Contributions: Bangyan Zhu designed the proposed approach and performed the experiments. Jiancheng Li supervised all work. All together evaluated the results and wrote the paper.

Conflicts of Interest: The authors declare no conflict of interest.

\section{References}

1. Thayer, G. An improved equation for the radio refractive index of air. Radio Sci. 1974, 9, 803-807. [CrossRef]

2. Davis, J.; Herring, T.; Shapiro, I.; Rogers, A.; Elgered, G. Geodesy by radio interferometry: Effects of atmospheric modeling errors on estimates of baseline length. Radio Sci. 1985, 20, 1593-1607. [CrossRef] 
3. Gray, A.L.; Mattar, K.E.; Sofko, G. Influence of ionospheric electron density fluctuations on satellite radar interferometry. Geophys. Res. Lett. 2000, 27, 1451-1454. [CrossRef]

4. Zebker, H.A.; Rosen, P.; Hensley, S. Atmospheric effects in interferometric synthetic aperture radar surface deformation and topographic maps. J. Geophys. Res. 1997, 102, 7547-7563. [CrossRef]

5. Li, Z.W.; Ding, X.L.; Liu, G.X.; Huang, C. Atmospheric effects on InSAR measurements-A review. Geomat. Res. Australas. 2003, 79, 43-58.

6. Ding, X.L.; Li, Z.W.; Zhu, J.J.; Feng, G.C.; Long, J.P. Atmospheric effects on InSAR measurements and their mitigation. Sensors 2008, 8, 5426-5448. [CrossRef]

7. Hooper, A.; Bekaert, D.; Spaans, K.; Arikan, M. Recent advances in SAR interferometry time series analysis for measuring crustal deformation. Tectonophysics 2012, 514-517, 1-13. [CrossRef]

8. Onn, F.; Zebker, H.A. Correction for interferometric synthetic aperture radar atmospheric phase artifacts using time series of zenith wet delay observations from a GPS network. J. Geophy. Res. 2006, 111. [CrossRef]

9. Mateus, P.; Nico, G.; Tomé, R.; Catalāo, J.; Miranda, P. Experimental study on the atmospheric delay based on GPS, SAR interferometry, and numerical weather model data. IEEE Trans. Geosci. Remote Sens. 2013, 51, 6-11. [CrossRef]

10. Wadge, G.; Webley, P.W.; James, I.N.; Bingley, R.; Dodson, A.; Waugh, S.; Veneboer, T.; Puglisi, G.; Mattia, M.; Baker, D.; et al. Atmospheric models, GPS and InSAR measurements of the atmospheric water vapor field over mount Etna. Geophys. Res. Lett. 2002, 29, 11-1-11-4. [CrossRef]

11. Foster, J.; Brooks, B.; Cherubini, T.; Shacat, C.; Businger, S.; Werner, C.L. Mitigating atmospheric noise for InSAR using a high resolution weather model. Geophys. Res. Lett. 2006, 33, L16304. [CrossRef]

12. Li, Z. Interferometric synthetic aperture radar (InSAR) atmospheric correction: GPS, Moderate Resolution Imaging Spectroradiometer (MODIS), and InSAR integration. J. Geophys. Res. 2005, 110. [CrossRef]

13. Li, Z.; Fielding, E.J.; Cross, P.; Muller, J.-P. Interferometric synthetic aperture radar atmospheric correction: Medium Resolution Imaging Spectrometer and Advanced Synthetic Aperture Radar integration. Geophys. Res. Lett. 2006, 33. [CrossRef]

14. Doin, M.P.; Lasserre, C.; Peltzer, G.; Cavalié, O.; Doubre, C. Corrections of stratified atmospheric delays in SAR interferometry: Validation with global atmospheric models. J. Appl. Geophys. 2009, 69, 35-50. [CrossRef]

15. Jolivet, R.; Grandin, R.; Lasserre, C.; Doin, M.P.; Peltzer, G. Systematic InSAR atmospheric phase delay corrections from global meteorological reanalysis data. Geophys. Res. Lett. 2011, 38. [CrossRef]

16. Delacourt, C.; Briole, P.; Achache, J. Atmospheric corrections of SAR interferograms with strong topography. Application to Etna. Geophys. Res. Lett. 1998, 25, 2849-2852. [CrossRef]

17. Burgmann, R.; Rosen, P.; Fielding, E. Synthetic aperture radar interferometry to measure Earth's surface topography and its deformation. Annu. Rev. Earth Planet. Sci. 2000, 28, 169-209. [CrossRef]

18. Lin, Y.; Simons, M.; Hetland, E.; Muse, P.; DiCaprio, C. A multiscale approach to estimating topographically correlated propagation delays in radar interferograms. Geochem. Geophys. Geosyst. 2010, 11, Q09002. [CrossRef]

19. Bekaert, D.; Hooper, A.; Wright, T. A spatially variable powerlaw atmospheric correction technique for InSAR data. J. Geophys. Res. 2015, 120, 1345-1356. [CrossRef]

20. Xu, P.L. Sign-constrained robust least squares, subjective breakdown point and the effect of weights of observations on robustness. J. Geod. 2005, 79, 146-159. [CrossRef]

21. Guo, J.F.; Ou, J.K.; Wang, H.T. Robust estimation for correlated observations: Two local sensitivity-based downweighting strategies. J. Geod. 2010, 84, 243-250. [CrossRef]

22. Kampes, B.; Hanssen, R.; Perski, Z. Radar interferometry with public domain tools. In Proceedings of the Fringe Workshop, Frascati, Italy, 1-5 December 2003; p. 6.

23. Hooper, A. Persistent Scatterer Radar Interferometry for Crustal Deformation Studies and Modeling of Volcanic Deformation; Stanford University: Stanford, CA, USA, 2006.

24. Hooper, A.; Zebker, H. Phase unwrapping in three dimensions with application to InSAR time series. J. Opt. Soc. Am. A 2007, 24, 2737-2747. [CrossRef]

25. Farr, G.T.; Kobrick, M. Shuttle radar topography mission produces a wealth of data. Eos Trans. AGU 2000, 81, 583-585.

26. Wright, T.; Fielding, E.; Parsons, B. Triggered slip: Observations of the 17 August 1999 Izmit (Turkey) earthquake using radar interferometry. Geophys. Res. Lett. 2001, 28, 1079-1082. [CrossRef] 
27. Cavalie, O.; Pathier, E.; Radiguet, M.; Vergnolle, M.; Cotte, N.; Walpersdorf, A.; Kostoglodov, V.; Cotton, F. Slow slip event in the Mexican subduction zone: Evidence of shallower slip in the Guerrero seismic gap for the 2006 event revealed by the joint inversion of InSAR and GPS data. Earth Planet. Sci. Lett. 2013, 367, 52-60. [CrossRef]

28. Hanssen, R.F. Radar Interferometry: Data Interpretation and Error Analysis; Kluwer Academic Publishers: Dordrecht, The Netherlands, 2001.

29. DiCaprio, C.; Simons, M. Importance of ocean tidal load corrections for differential InSAR. Geophys. Res. Lett. 2008, 35, L22309. [CrossRef]

30. Bekaert, D.; Hooper, A.; Wright, T. Reassessing the 2006 Guerrero slow slip event, Mexico: Implications for large earthquakes in the Guerrero Gap. J. Geophys. Res. Solid Earth 2015, 120, 1357-1375. [CrossRef]

31. Fu, Y.; Freymueller, J.T.; Jensen, T. Seasonal hydrological loading in southern Alaska observed by GPS and GRACE. Geophys. Res. Lett. 2012, 39, L15310. [CrossRef]

32. Yang, Y. Robust estimation for dependent observations. Manuscr. Geod. 1994, 19, 10K-17K.

33. Yang, Y.; Cheng, M.K.; Shum, C.K.; Tapley, B.D. Robust estimation of systematic errors of satellite laser range. J. Geod. 1999, 73, 345-349. [CrossRef]

34. Huber, P.J. Robust Statistics; John Wiley and Sons: New York, NY, USA, 1981.

35. Li, Z.W.; Xu, W.B.; Feng, G.C.; Hu, J.; Wang, C.C.; Ding, X.L.; Zhu, J.J. Correcting atmospheric effects on InSAR with MERIS water vapor data and elevation-dependent interpolation model. Geophys. J. Int. 2012, 189, 898-910. [CrossRef]

(C) 2016 by the authors; licensee MDPI, Basel, Switzerland. This article is an open access article distributed under the terms and conditions of the Creative Commons Attribution (CC-BY) license (http://creativecommons.org/licenses/by/4.0/). 